\title{
Large1 Gene Transfer in Older myd Mice with Severe Muscular Dystrophy Restores Muscle Function and Greatly Improves Survival
}

Takahiro Yonekawa ${ }^{1}$, Adam J. Rauckhorst ${ }^{2}$, Sara El-Hattab ${ }^{1}$, Marco A. Cuellar ${ }^{1}$, David Venzke ${ }^{1}$, Mary E. Anderson ${ }^{1}$, Hidehiko Okuma ${ }^{1}$, Alvin D. Pewa ${ }^{2}$, Eric B. Taylor ${ }^{2 *}$, Kevin P. Campbell ${ }^{1 *}$

${ }^{1}$ Howard Hughes Medical Institute, Senator Paul D. Wellstone Muscular Dystrophy Specialized Research Center, Department of Molecular Physiology and Biophysics and Department of Neurology, Roy J. and Lucille A. Carver College of Medicine, The University of Iowa, Iowa City, Iowa 52242, USA

2 Department of Molecular Physiology and Biophysics, Fraternal Order of Eagles Diabetes Research Center (FOEDRC), and FOEDRC Metabolomics Core Facility, Roy J. and Lucille A. Carver College of Medicine, University of Iowa, Iowa City, IA 52242, USA

* Corresponding authors 


\section{Yonekawa et al.}

\section{ABSTRACT:}

Muscular dystrophy is a progressive and ultimately lethal neuromuscular disease due to lack of therapeutic options that restore muscle function. Gene editing and gene transfer hold great promise as therapies for various neuromuscular diseases when administered prior to the onset of severe clinical symptoms. However, the efficacy of these strategies for restoring neuromuscular function and improving survival in the late stages of muscular dystrophy with severe muscle pathophysiology is unknown. Dystroglycanopathies are muscular dystrophies characterized by extensive skeletal muscle degeneration and, in many cases, are accompanied by eye and brain abnormalities. Thus far, mutations in at least eighteen human genes are known to cause dystroglycanopathies, including those in the like-acetylglucosaminyltransferase-1 (LARGE1) gene. $L A R G E 1$ encodes a xylosyl- and glucuronosyltransferase that modifies $\alpha$-dystroglycan $(\alpha$ DG) with matriglycan, a linear repeating disaccharide of alternating xylose and glucuronic acid that binds to the laminin G-like domains of extracellular matrix proteins with high affinity. Large $^{\text {myd }} /$ Large $^{\text {myd }}$ (myd) mice lack expression of Large1, and exhibit severe skeletal muscle pathophysiology, impaired mobility, and a drastically reduced lifespan (50\% survivorship at 35 weeks of age). Here, we show that systemic delivery of AAV2/9 CMV Large1 (AAVLarge1) in >34-week-old myd mice with advanced disease restores matriglycan expression, attenuates skeletal muscle pathophysiology, improves motor and respiratory function, and normalizes systemic metabolism, which collectively and dramatically extends survival. Our results demonstrate that in a mouse model of muscular dystrophy, skeletal muscle function can be restored, illustrating its remarkable plasticity, and that survival can be greatly improved even after the onset of severe skeletal muscle pathophysiology. 
Yonekawa et al.

\section{INTRODUCTION:}

Substantial progress has been made toward unraveling the genetic basis of various muscular dystrophies, yet existing therapies are limited and do not prevent the unchecked skeletal-muscle degeneration that eventually leads to death. Gene therapy is an attractive approach for these individuals as it enables the delivery of a functional copy of a gene or repairs the mutated locus (for reviews see 1-5). Recently, AAV-mediated gene transfer has shown great promise for treating patients with neuromuscular diseases, such as spinal muscular atrophy, when administered before severe clinical symptoms arise (6). Similarly, preclinical studies in which adenoviral gene transfer or gene editing is administered at a young age prior to the onset of severe symptoms shows great promise in various mouse models of muscular dystrophy (7-15). However, the efficacy of AAV-mediated gene therapy in treating severe muscle degeneration associated with advanced stages of muscular dystrophy is unknown.

Dystroglycanopathies are a group of congenital/limb-girdle muscular dystrophies with or without eye and brain abnormalities and are caused by defects in $O$-glycosylation or posttranslational processing of $\alpha$-dystroglycan ( $\alpha$-DG), the cell-surface subunit of dystroglycan (DG) (16-18). DG is a widely expressed high-affinity extracellular matrix (ECM) receptor (19) that is highly glycosylated and involved in a variety of physiological processes, which include maintaining the integrity of the skeletal muscle membrane and the structure and function of the central nervous system (16-17). In skeletal muscle, DG is part of the dystrophin-glycoprotein complex, which establishes a continuous link between laminin-G-like (LG) domains of ECMresident proteins (laminin, agrin, and perlecan) and the cytoskeleton (19-22).

Dystroglycanopathies are characterized by an absence or reduction in matriglycan, a unique heteropolysaccharide on $\alpha$-DG that binds with high-affinity to laminin G-like domains of ECM proteins (23-24). Thus far, at least eighteen causative genes for dystroglycanopathies have been 
Yonekawa et al.

identified in humans, including mutations in the like-acetylglucosaminyltransferase-1 (LARGE1) gene that cause a severe form of congenital muscular dystrophy (25-27).

Large $e^{m y d} /$ Large $e^{m y d}(m y d)$ mice are an excellent model for therapeutic studies of dystroglycanopathies because they lack matriglycan and exhibit severe skeletal muscle pathophysiology, impaired mobility, reduced body weight, and a drastically reduced lifespan (16, 28-30). Using both non-invasive and invasive techniques, we performed a comprehensive study to test the ability of systemic AAV-mediated gene transfer of Large1 to improve skeletal muscle function and survival in myd mice with advanced disease. We show that this treatment in older myd mice with severe muscular dystrophy attenuates skeletal muscle degeneration and improves motor and respiratory function as well as systemic metabolism, which collectively extends survival of myd mice. Thus, our study provides proof-of-concept that functional and pathological features of muscular dystrophy are treatable, even after severe muscle degeneration is established.

\section{RESULTS:}

To evaluate the therapeutic effect of treating established dystroglycanopathy, we targeted aged myd mice as they exhibited severe muscle pathophysiology. Prior to gene transfer studies, we analyzed the progression of disease in our Large $e^{m y d} / \operatorname{Large}^{\text {myd }}$ (myd) mouse colony on the C57BL/6 genetic background $(92.5 \% \mathrm{C} 57 \mathrm{BL} / 6)$ from the newborn period to 35 weeks of age. myd mice were generated by mating heterozygous $+/$ myd mice and were significantly smaller than their littermates $(+/+$ or $+/ m y d)$ at postnatal day three, weighing $1.8 \pm 0.3 \mathrm{~g}($ mean $\pm \mathrm{SD}, \mathrm{n}=$ 18) versus $2.2 \pm 0.5 \mathrm{~g}(\mathrm{n}=143)$. myd mice also showed consistently slower growth compared to littermate controls, although males and females continued to grow until 20 or 15 weeks of age, respectively, after which they exhibited a significant decline in body weight (Figs. S1a and b). At 
35 weeks of age, the weight of myd mice was markedly less than that of littermate controls: 21.4 $\pm 2.7 \mathrm{~g}($ myd $)$ versus $42.4 \pm 6.1 \mathrm{~g}$ (littermate controls) in male and $16.7 \pm 2.7($ myd $)$ versus $34.2 \pm$ $5.5 \mathrm{~g}$ (littermate controls) in female. The survival of myd mice was considerably shorter than that of littermate controls, with only $35 \%$ surviving to 40 weeks of age and no mice living past 60 weeks of age (Fig. S1c). Additionally, thoracic kyphosis and muscle wasting were evident at $\sim 40$ weeks of age in myd mice (Fig. S1d). Fibrous and adipose tissue infiltration was prominent in myd mice that were older than 35 weeks, with numerous small, round-shaped fibers observed upon histological analysis, indicative of end-stage pathology (Figs. S2a, S2b). Matriglycan positive $\alpha$-DG (functionally glycosylated) was localized in the muscle sarcolemma of C57BL/6 (WT) mice but absent in myd mice (Fig. S2c).

We next performed systemic AAV-mediated gene transfer of Largel in adult myd mice (at approximately 50\% survivorship age) with severe skeletal muscle pathophysiology and assessed the effects on muscle function and survival. We randomly assigned 35 myd mice that were 34 weeks or older to untreated or treated groups. Twenty-one mice were left untreated whereas fourteen mice were injected once with AAVLargel at age $38.4 \pm 2.8$ weeks (mean \pm SD). A series of non-invasive and invasive therapeutic readouts were compared between the two groups, including: body weight, survival, muscle and respiratory function, muscle physiology, histological evaluation, plasma metabolomics, and biochemical analysis of $\alpha$-DG. Mice were weighed weekly and locomotor activity was assessed every four weeks (see Fig. 1a experimental outline). Body weight and locomotor activity were compared between baseline (i.e., at enrollment for untreated group or before AAVLarge1 injection for treated group) and each assessment time point. Respiratory function was assessed before untreated mice were euthanized or when AAV-treated mice reached 60 weeks of age. Muscle physiology was evaluated 
Yonekawa et al.

immediately prior to euthanasia and tissues were subsequently harvested for further analysis.

Untreated myd mice (34-35 weeks old) showed a marked reduction in locomotor activity, as measured by distance traveled, or rearing behavior, as measured by vertical activity, and displayed progressive deterioration in motor performance until euthanasia was necessary (Figs. 1b, c) compared to 37-week-old WT mice (Fig. S3). In contrast, AAV-mediated gene transfer of Largel in myd mice restored locomotor and rearing activities, and mice were able to maintain motor performance until they were euthanized for analysis at age $69.7 \pm 5.1$ weeks (Figs. 1b, c).

Forelimb grip strength was also markedly reduced in 46.5-week-old myd mice relative to WT mice aged 61.1 weeks (Fig. 1d). The muscle weight and cross-sectional area (CSA) of dissected extensor digitorum longus (EDL) muscles were smaller (Figs. 1e, 1f), and the absolute isometric tetanic force $\left(\mathrm{F}_{\mathrm{o}}\right)$ and the size-normalized isometric tetanic force $\left(\mathrm{F}_{\mathrm{o}} / \mathrm{CSA}\right)$ were markedly lower in myd mice compared to those of WT mice (Figs. 1g, 1h), suggesting that the muscles were not only atrophic but also highly degenerated. In contrast, AAVLargel-treated myd mice showed a significant increase in forelimb grip strength (Fig. 1d); however, the muscle weight and CSA of isolated EDL muscles only increased modestly (Figs. 1e, 1f).

Systemic transduction of myd mice with AAVLarge1 of myd mice also resulted in a significant increase in isometric tetanic force $\left(\mathrm{F}_{\mathrm{o}}\right)$ and specific isometric tetanic force $\left(\mathrm{F}_{\mathrm{o}} / \mathrm{CSA}\right)$ of EDL muscles compared to untreated mice (Figs. 1g, h), demonstrating that even at advanced stages of disease muscle contractile properties can be improved by delivering a functional copy of Large 1. Additionally, EDL muscles in untreated mice were highly susceptible to injury induced by eccentric contractions (ECCs), and tetanic $\mathrm{F}_{\mathrm{o}}$ force dropped by $63 \%$ after the $3^{\text {rd }} \mathrm{ECC}$ (Fig 1i). In contrast, EDL muscles in AAVLargel-treated mice tolerated a sequence of five ECCs, although the force drops induced by the ECC protocol were slightly greater than those in 
WT muscles (Fig. 1i). It should be noted that muscle size, contractile properties, and lengthening contraction-induced muscle damage is similar in EDL muscles from $+/+$ or $+/$ myd mice (Fig. S4).

At 35 weeks of age (just before AAV treatment), there was no significant difference in body weights between myd mice that were untreated or treated with AAVLarge1 (Fig. S5a). However, after 35 weeks, untreated myd mice displayed a significant decline in body weight that progressed until euthanasia was required (Fig. 1j), whereas systemic gene transfer of Largel resulted in a mild gain in body weight (Fig. 1j). All surviving myd mice older than 35 weeks of age were very thin, suggesting they had already developed severe muscle atrophy and degeneration, and they continued to decline without treatment (Fig. S5b, left). Indeed, the sizes of the gastrocnemius and quadriceps femoris muscles were markedly smaller in myd mice compared to those of WT mice. Nevertheless, AAV-mediated gene transfer of Largel resulted in mild growth of these muscles (Figs. S5c-f), although treated mice still looked thin (Fig. S5b, right), suggesting these muscles may be too severely affected at later stages of disease to recover to normal weights. Strikingly, AAV-mediated gene transfer significantly extended the survival of myd mice, as all but one mouse injected with AAVLargel lived to $>65$ weeks of age, whereas only $50 \%$ of the myd mice survived to 45 weeks of age (Fig. 1k).

As expected, myd muscles did not express Largel and the level of Largel expression in $+/$ myd muscles was approximately half that observed in muscles from WT or $+/+$ mice (Fig. 2a). Western blot analysis of WGA-enriched myd muscle homogenates demonstrated that the transmembrane subunit of DG, $\beta$-dystroglycan ( $\beta$-DG), was normally expressed whereas functional $\alpha$-DG was absent in myd muscles, as assessed by reactivity to the IIH6 antibody (antimatriglycan) or the laminin overlay assay (Fig. 2b). In addition, $\alpha$-DG-ligand binding was severely affected in myd muscles compared to WT muscles (Fig. 2c) corresponding to the fact 
Yonekawa et al.

that myd EDL muscles were highly susceptible to lengthening contractions (Fig. 1i). Of note, the quadriceps and EDL muscles in +/myd mice exhibited no difference in biochemical and physiological features, respectively, when compared to WT or $+/+$ muscles (Figs. 2b and S4). The level of Largel expression in +/myd (+/-) muscles was around half of that of WT or +/+ levels (Fig. 2a), and +/myd muscles showed no biochemical or physiological abnormalities (Figs. $2 \mathrm{~b}$ and $\mathrm{S} 4)$.

AAV-mediated gene transfer resulted in overexpression of Largel in myd mice, leading to hyperglycosylation of $\alpha$-DG in the muscle sarcolemma (Figs. 2a, 2b) as previously observed with adenovirus expressing Large1 (12). Western blotting of WGA-enriched muscle homogenates after AAV-mediated systemic transduction showed that $\alpha$-DG was highly glycosylated with matriglycan and bound laminin (Fig. 2b). Furthermore, restoring Large1 expression in myd mice rescued $\alpha$-DG-ligand binding (Fig. 2c), explaining the observation that EDL muscles were protected from ECC-induced damage.

The improved phenotype in muscle size and function observed in myd mice upon AAVmediated gene transfer of Largel prompted us to determine if this treatment also improved skeletal muscle pathology. As expected, histological analysis of skeletal muscle in untreated myd mice showed marked variation in fiber size, numerous fibers with central nuclei, adipose tissue infiltration, and fibrosis (Fig. 2d). Immunofluorescence analysis also showed a lack of matriglycan on $\alpha$-DG in untreated myd mice (Fig. 2d). In contrast, quantification of matriglycanpositive $\alpha$-DG fibers revealed that almost all fibers expressed functional $\alpha$-DG in myd mice after injection with AAVLargel (Fig. 2e). Furthermore, progression of fibrous tissue deposition was halted in treated mice when compared to untreated mice (Fig. 2f). In the absence of Largel expression, mice exhibited muscle wasting (Figs. S5c-f), associated with muscle fiber atrophy as 
Yonekawa et al.

revealed by an overall decrease in fiber diameter in untreated myd quadriceps femoris muscles (Fig. 2g), with a higher proportion of fiber diameters of 10-20 $\mu \mathrm{m}$ (Fig. 2h). In contrast, AAVmediated overexpression of Largel increased overall muscle fiber diameter, as demonstrated by a greater percentage of fibers having a larger fiber diameter (Figs. 2g, 2h).

Respiratory function is impaired in myd mice (28-30), as demonstrated by a marked reduction in tidal volume (TV) and minute volume (MV) compared to WT mice or littermate controls (Figs. 3a, 3b). Moreover, myd mice displayed lower TV and MV normalized to body weight (TV/BW and MV/BW) than WT mice or littermate controls (Figs. 3c, 3d). A respiratory function test revealed that myd mice treated with AAVLargel had a higher TV and MV than untreated mice (Figs. 3a and b), indicating that treated mice exhibit reduced forced breathing compared to untreated mice. In addition, TV/BW was moderately increased in treated mice verses untreated mice, whereas MV/BW was unaffected (Figs. 3c, 3d), demonstrating that AAVmediated overexpression of Largel ameliorated defects in respiratory muscle function.

We next investigated whether systemic gene transfer improves diaphragm pathology in myd mice. In untreated mice, fibrous tissue infiltration was prominent, and no muscle fibers expressed glycosylated $\alpha$-DG (Figs. 3e, 3f). In contrast, treatment with AAVLarge1 restored expression of glycosylated $\alpha$-DG to similar levels observed in WT mice (Fig. 3f). Progression of connective tissue deposition was also prevented by AAV-mediated gene transfer of Large1 relative to untreated mice (Fig. 3g). In addition, the overall fiber diameter of diaphragm muscles was increased (Fig. 3h), and an increased percentage of muscle fibers had a larger fiber diameter upon overexpression of Largel (Fig. 3i). Thus, AAV-mediated gene transfer of Largel caused muscle fibers in the diaphragm to increase in diameter, thus improving respiratory function.

We further investigated whether systemic gene delivery using AAV restores matriglycan 
Yonekawa et al.

on $\alpha$-DG in cardiomyocytes in myd mice. No obvious pathology was observed in the absence of Large1 (Fig. S6a). Immunofluorescence analysis revealed that expression of glycosylated $\alpha$-DG was remarkably restored in hearts of myd mice treated with AAVLargel and was likely due to restored expression of the Large1 gene (Figs. S6a, 6b). Of note, the subendocardial portion was less transduced (Fig. S6a) indicating AAV transduction is less efficient in this region. No difference in connective tissue infiltration was observed between untreated and treated mice, although two mice that were treated with AAVLargel had focal fibrous tissue deposition (Fig. S6c). Therefore, AAV-mediated gene delivery of Large1 restores glycosylated $\alpha$-DG in cardiomyocytes, although the effects of this on cardiomyocyte function are difficult to discern in the myd mouse given the lack of phenotype in the heart in our myd mouse colony.

Skeletal muscle metabolism is a critical regulator of systemic metabolism that becomes abnormal in muscular dystrophies (31-34). The plasma metabolome is a useful read-out of whole-body metabolism that reflects changes in muscle metabolism resulting from both altered basal nutrient utilization and locomotive activity. To determine the efficacy of AAVLargel gene transfer in normalizing whole-body metabolism, we performed targeted metabolomic profiling on plasma from myd mice with advanced disease. The plasma metabolome was abnormal in myd mice, with significant changes observed in 21 of 78 measured plasma metabolites, 10 of which were normalized upon AAVLarge1 gene transfer (Table S1). Notably, glycolytic (Fig 4a) and TCA cycle (Fig 4b) intermediates were enriched among altered metabolites, especially those restored by AAVLarge1. myd mice exhibited increased early and mid-glycolytic intermediates and decreased lactate, suggesting altered coupling of early and late glycolysis (Fig 4a). In parallel, TCA cycle intermediates malate, fumarate, and $\alpha$-ketoglutarate were decreased, consistent with decreased TCA cycle amino acid influx through $\alpha$-ketoglutarate in the absence of 
Yonekawa et al.

Large1 (Fig 4b). Overall, the metabolomic profiling of plasma showed that systemic metabolism normalized following treatment with AAVLargel.

\section{DISCUSSION:}

Current therapies available to muscular dystrophy patients are limited and neither restore normal skeletal muscle function nor improve survival. Gene therapy is an exciting therapeutic approach for the treatment of muscular dystrophy as it enables the delivery of a functional copy of a gene or repairs the mutated locus. Preclinical studies using AAV-mediated gene transfer or gene editing to treat various mouse models of muscular dystrophy at a young age have been very successful in preventing skeletal muscle pathophysiology (7-15). However, the use of gene transfer has been difficult to study when applied as a treatment in the late stages, after the onset of severe muscle pathophysiology. Yet, these "restoration" studies are particularly important since many patients with muscular dystrophy have skeletal muscle degeneration before the onset of clinical symptoms and are often not diagnosed or treated until after these symptoms arise. Thus, we seek to understand the ability of gene therapy to repair severely damaged skeletal muscle and improve survival.

Our previous work with Largel gene transfer using adenovirus required direct muscle injections into young myd mice and showed localized prevention of dystrophic pathology (12). In addition, Largel gene transfer into healthy muscle did not cause abnormalities even though Large 1 was highly overexpressed and $\alpha$-DG was hyperglycosylated (12). Here, in order to test if severely damaged skeletal muscle can be repaired and overall lifespan improved, we performed a comprehensive study using systemic AAV-mediated gene transfer of Largel in myd mice with advanced disease. Since $\alpha-\mathrm{DG}$ and Large 1 are widely expressed, we used the CMV promoter to drive Largel expression and ensure $\alpha$-DG glycosylation was restored. To evaluate the 
effectiveness of AAV-mediated gene transfer of Large1, we used various therapeutic readouts, including body weight, survival, muscle and respiratory function, muscle physiology, histological evaluation, plasma metabolomics, and biochemical analysis of $\alpha$-DG.

We first used non-invasive techniques to monitor the effectiveness of systemic treatment with AAVLargel to restore muscle function in older myd mice. Both locomotor and rearing activities were restored, and mice were able to maintain motor performance. AAVLargel-treated myd mice also showed a significant increase in forelimb grip strength. Moreover, AAV-mediated expression of Largel ameliorated defects in respiratory muscle function and normalized systemic metabolism, as determined by metabolomic profiling on plasma. Although the precise mechanisms underlying these metabolomic changes must still be determined, these results identify plasma metabolic signatures that are associated with the absence of Largel in myd mice, and that are restored upon AAVLargel gene transfer. Consequently, future studies should avail themselves to plasma metabolomics, as it is a non-invasive, powerful, multivariate method to surveil the efficacy of gene therapy.

In addition, untreated myd mice displayed a significant decline in body weight that progressed until euthanasia was required, whereas systemic gene transfer of Largel resulted in a mild gain in body weight. Perhaps the most remarkable was the ability of AAVLarge1 to significantly extend the survival of older myd mice. Strikingly, all but one mouse injected with AAVLargel lived to $>65$ weeks of age, whereas only $50 \%$ of untreated myd mice survived to 45 weeks of age. Thus, results from our non-invasive assays provide evidence that $\alpha$-DG function is restored following systemic treatment with AAVLarge1, and that this has a significant impact on survival.

To further support our findings from non-invasive assays, we performed invasive analysis 
Yonekawa et al.

of muscle following euthanasia of mice treated with AAVLarge1. Western blotting analysis and quantitative solid phase laminin binding assays demonstrated that AAVLargel was able to restore fully functional glycosylation of $\alpha$-DG. Systemic transduction with AAVLargel in myd mice resulted in a significant increase in isometric tetanic force $\left(\mathrm{F}_{\mathrm{o}}\right)$ and specific isometric tetanic force $\left(\mathrm{F}_{\mathrm{o}} / \mathrm{CSA}\right)$ of EDL muscles compared to untreated mice, demonstrating that muscle contractile properties can be improved, even at advanced stages of disease. Additionally, EDL muscles in AAVLargel-treated mice tolerated a sequence of eccentric contractions in a manner that was largely similar to that of WT mice. Collectively, our histological, biochemical, and physiological analysis of muscle show that glycosylation of $\alpha$-DG is restored, and muscle function improved in myd mice treated with AAVLargel.

Individuals with muscular dystrophy are commonly diagnosed after the onset of clinical symptoms, yet current treatments are unable to restore the function of degenerated muscles. We show that AAVLarge1 gene transfer in older myd mice with severe muscular dystrophy attenuates skeletal muscle degeneration, improves motor and respiratory function, and normalizes systemic metabolism, which collectively extends survival of myd mice. Furthermore, our results demonstrate that skeletal muscle has remarkable plasticity, suggesting that gene therapy that is aimed at rescuing deficits in gene function harbors the potential to effectively restore muscle function. Thus, this study provides proof-of-concept that functional and pathological features of muscular dystrophy are reversible, even in advanced stages of disease.

\section{METHODS:}

\section{Experimental design}

We set out to evaluate the therapeutic effect of treating established $\alpha$-dystroglycanopathy; therefore, we targeted aged, severely affected $\operatorname{Large}^{m y d} / \operatorname{Large}^{m y d}$ (myd) mice as they exhibit end- 
Yonekawa et al.

stage muscle pathophysiology. The myd mouse is a natural model of glycosylation-deficient muscular dystrophy (14), with $65 \%$ of animals dying before 40 weeks of age (7-9). Previous work involving Largel gene transfer with adenovirus used direct muscle injections into young myd mice and showed localized prevention of dystrophic pathology (12). Successful systemic gene transfer using $10^{12}-10^{13} \mathrm{vg} /$ mouse via intraperitoneal or intravenous injections has previously been established for serotype 9, especially in skeletal muscle and heart (8-13). Therefore, we choose to use the AAV2/9 vector with a CMV promoter to systemically administer Large1 to myd mice. Thirty-five surviving myd mice that were 34 weeks or older were randomly assigned to untreated or treated groups. In the treated group, a total of 14 mice were injected once intraperitoneally $(n=3)$ or once intravenously $(n=11)$ with AAV2/9CMVLarge1 (AAVLarge1) at a vector dose of $4.35 \times 10^{12} \mathrm{vg} / \mathrm{mouse}$. Twenty-one mice were left untreated. Therapeutic readouts were body weight, survival, muscle and respiratory function, muscle physiology, histological evaluation, plasma metabolomics, and biochemical analysis of $\alpha$-DG (see Fig. 1a for experimental outline). The mice were weighed weekly and locomotor activity was assessed every four weeks. The respiratory function test was performed just before untreated mice were euthanized or when AAV-treated mice became 60 weeks old.

\section{$\underline{\text { Animal Care and Criterion for euthanasia }}$}

Mice were maintained in a barrier-free, specific pathogen-free grade facility and had access to normal chow and water ad libitum. All animals were manipulated in biosafety cabinets and change stations using aseptic procedures. The mice were maintained in a climate-controlled environment at $25^{\circ} \mathrm{C}$ on a $12 / 12$ hour light/dark cycle. All animal protocols were approved by the University of Iowa Animal Care and Use Committee (IACUC). MYD/Le-Os+/+Large $e^{m y d} / \mathrm{J}$ mice (JAX stock \#000300) were maintained on a C57BL/6J (WT) background and colony 
maintenance was carried out in the laboratory by mating +/myd males to +/myd females. myd mice and control littermate mice $(+/+$ or $+/ m y d$ mice) were identified via PCR.

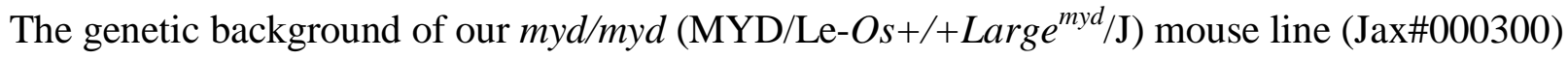
was tested at Transnetyx (Cordova, TN) with an array-based platform using over 10,000 SNP markers, which showed the line has a 92.5\% C57BL/6 genetic background. Animal care, ethical usage, and procedures were approved and performed in accordance with the standards set for the by the National Institutes of Health and IACUC. Of the 161 offspring from heterozygous $+/ m y d$ matings, only $18(11.2 \%)$ were homozygotes $(m y d / m y d)$. Theoretically, there is a $25 \%$ chance that a homozygote is produced, suggesting some homozygotes could be embryonic lethal. Surviving myd mice older than 35 weeks of age required gruel feeding in the cage, as they were too weak to reach food pellets suspended overhead. Due to the progressive deterioration in motor and respiratory function with age, myd mice were euthanized due to an inability to feed, hind limb paralysis, reduced body score, or respiratory distress, as dictated in our IACUC protocol.

\section{$\underline{\mathrm{AAV} \text { vector production and } \mathrm{AAV} \text { injection }}$}

The sequence encoding mouse like-acetylglucosaminyltransferase-1 (Large1) was synthesized (Genscript, Piscataway, NJ) and cloned into the AAV backbone under the transcriptional control of the ubiquitous CMV promoter. The AAV2/9 vector contains the genome of serotype 2 packaged in the capsid from serotype 9 and was selected due to its ability to improve muscle transduction efficiency as well as alter tropism. The vector AAV2/9CMVLargel was generated by the University of Iowa Viral Vector Core Facility. For adult mice, 100 microliters $\left(4.35 \times 10^{12}\right.$ vg) of the vector solution was administered once intraperitoneally or intravenously via the retro orbital (RO) sinus. 
Yonekawa et al.

\section{$\underline{\text { Locomotor activity }}$}

Locomotor activity was measured using an open-field Digiscan apparatus (Omnitech Electronics, Columbus, $\mathrm{OH})$. The mice were acclimated to the open-field apparatus for three days prior to the first trial. Total walking distance and rearing behavior (vertical activity) were recorded every 10 minutes for one hour when the mice were in active phase. Activity data were collected for two consecutive days and the higher of the two values for each parameter was used for analysis.

\section{Forelimb grip strength test}

The forelimb grip strength test was performed when mice were eight weeks of age in the preventive study and 60 weeks of age in the therapeutic study. A mouse grip strength meter (Columbus Instruments, Columbus, $\mathrm{OH}$ ) was mounted horizontally, with a nonflexible grid connected to the force transducer, which shows the highest force applied by the mouse on the grid during the pull. The mouse was allowed to grasp the grid with its front paws and then pulled away from the grid so that its grasp was broken. The gram force was recorded per pull, but measures were rejected in which only one forepaw or the hind limbs were used, and in which the mouse turned during the pull. A total of 15 pulls (five series of three pulls in a row) were performed, with a resting period between series to allow the mouse to recover and avoid habit formation. The three highest values out of the 15 values collected were used to determine the maximum grip strength, which was normalized for body weight.

\section{Plethysmography}

Respiratory function was tested in unrestrained mice using a whole-body plethysmograph (Buxco Respiratory Products, Data Sciences International, St. Paul, MN). The mouse was weighed and placed into the chamber for 15 minutes to acclimate and respiratory flow data was recorded for five minutes using FinePointe software (Data Sciences International, St. Paul, MN). 
Yonekawa et al.

The measurements were done for two consecutive days. For data analysis, average values for tidal volume (TV), minute volume (MV), TV normalized by body weight (TV/BW), and MV normalized by body weight (MV/BW) were used.

\section{Measurement of in vitro muscle function}

To compare the contractile properties of muscles, EDL muscles were surgically removed and analyzed as described previously $(35,36)$, with minor modifications. The muscle was immediately placed in a bath containing a buffered physiological salt solution (composition in mM: $\mathrm{NaCl}, 137 ; \mathrm{KCl}, 5 ; \mathrm{CaCl}_{2}, 2 ; \mathrm{MgSO}_{4}, 1 ; \mathrm{NaH}_{2} \mathrm{PO}_{4}, 1 ; \mathrm{NaHCO}_{3}, 24 ;$ glucose, 11). The bath was maintained at $25^{\circ} \mathrm{C}$, and the solution was bubbled with $95 \% \mathrm{O}_{2}$ and $5 \% \mathrm{CO}_{2}$ to stabilize the $\mathrm{pH}$ at 7.4. The proximal tendon was clamped to a post and the distal tendon was tied to a dual mode servomotor (Model 305C; Aurora Scientific, Aurora, ON, Canada). Optimal current and whole muscle length $\left(\mathrm{L}_{\mathrm{o}}\right)$ were determined by monitoring isometric twitch force. Optimal frequency and maximal isometric tetanic force $\left(\mathrm{F}_{\mathrm{o}}\right)$ were also determined. The muscle was then subjected to an eccentric contraction (ECC) protocol consisting of five eccentric contractions (ECCs) separated by three-minute intervals. A fiber length $\left(\mathrm{L}_{\mathrm{f}}\right)$-to- $\mathrm{L}_{\mathrm{o}}$ ratio of 0.45 was used to calculate $\mathrm{L}_{\mathrm{f}}$. Each ECC consisted of an initial $100 \mathrm{~ms}$ isometric contraction at optimal frequency immediately followed by a stretch of $\mathrm{L}_{\mathrm{o}}$ to $30 \%$ of $\mathrm{L}_{\mathrm{f}}$ beyond $\mathrm{L}_{\mathrm{o}}$ at a velocity of one $\mathrm{L}_{\mathrm{f}} / \mathrm{s}$ at optimal frequency. The muscle was then passively returned to $\mathrm{L}_{\mathrm{o}}$ at the same velocity. At three, 15, 30, 45, and 60 minutes after the ECC protocol, isometric tetanic force was measured, and force deficit was calculated as the decrease in isometric tetanic force post-ECC as a percentage of $\mathrm{F}_{\mathrm{o}}$. After the analysis of the contractile properties, the muscle was weighed. The crosssectional area (CSA) of muscle was determined by dividing the muscle mass by the product of $\mathrm{L}_{\mathrm{f}}$ 
Yonekawa et al.

and the density of mammalian skeletal muscle $\left(1.06 \mathrm{~g} / \mathrm{cm}^{3}\right)$. The specific force was determined by dividing $\mathrm{F}_{\mathrm{o}}$ by the $\mathrm{CSA}\left(\mathrm{mN} / \mathrm{mm}^{2}\right)$.

\section{Tissue collection and histological evaluation}

Mice were euthanized by cervical dislocation and tissue samples were obtained. Quadriceps, gastrocnemius, tibialis anterior, and soleus muscles were weighed prior to processing.

Quadriceps and gastrocnemius muscles from the right side of the animal, half the diaphragm, and half the heart were snap frozen in Optimal Cutting Media (OCT), submerged in isopentane cooled in liquid nitrogen, and stored at $-80{ }^{\circ} \mathrm{C}$ for further analysis. The other skeletal muscles were frozen in liquid nitrogen and stored at $-80{ }^{\circ} \mathrm{C}$ for biochemical analysis. Cryosections of quadricep muscle, diaphragm, and heart were cut at a thickness of $7 \mu \mathrm{m}$ and stained with hematoxylin and eosin $(\mathrm{H} \& \mathrm{E})$ and Sirius red and Fast Green. For Sirius red staining, sections were fixed in $10 \%$ neutral buffered formalin (Thermo Fisher Scientific) for five minutes, followed by Sirius red staining consisting of a 30-minute incubation in $0.1 \%$ Sirius red F3B (1A 280; Chroma Gesellschaft, Germany) in saturated picric acid (Sigma-Aldrich, St Louis, MO), and several incubations with ethyl alcohol and xylene. Whole digital images of H\&E- and Sirius red-stained sections were taken by a VS120-S5-FL Olympus slide scanner microscope (Olympus Corporation, Tokyo, Japan). To quantify fibrous tissue infiltration in Sirius red-stained muscle and diaphragm sections, four fields were randomly selected from a whole section using OlyVIA ver.2.9 (Olympus) and the captured images were processed using Image J (NIH) with additional threshold color plug-ins to process jpeg images. Pixels corresponding to the area stained in red were normalized to the total pixel area of the image, and the four values were expressed as a percent of the fibrotic area and were averaged for each section. 
Yonekawa et al.

\section{Immunohistochemistry}

For morphometric analyses, transverse sections of the sarcolemma of muscle, diaphragm, and heart were stained with a rabbit polyclonal anti-caveolin three antibody (ab2912; Abcam, 1:100 dilution) and a mouse monoclonal antibody to glycoepitopes on the sugar chain of $\alpha$-DG (VIA41; $1: 10$ dilution) overnight at $4^{\circ} \mathrm{C}$, followed by staining with Alexa Fluor®-conjugated goat $\mathrm{IgG}$ against rabbit IgG and goat $\mathrm{IgG}$ against mouse $\mathrm{IgG}_{1}$ (Invitrogen, 1:400 dilution), respectively, for 40 minutes. The sections were counterstained with DAPI (Invitrogen) and whole sections were imaged with a VS120-S5-FL Olympus slide scanner microscope. Feret's diameter of muscle fibers were measured with VS-DESKTOP software (Olympus). To quantify fibers expressing glycosylated $\alpha$-dystroglycan, the percent of VIA41-positive fibers was determined by dividing the VIA41-positive fiber count by the anti-caveolin 3-positive fiber count. To quantify fibers with centrally located nuclei, three fields were randomly selected from a whole section and were double stained with anti-caveolin 3 antibody and DAPI. Total and centrally nucleated fibers (CNFs) were manually counted and \% CNF was determined by dividing CNF by total fiber count per each captured image. The three \%CNF values were averaged and compared. The sarcolemma of muscle and diaphragm sections were also stained with a rabbit monoclonal antibody to $\beta$-DG (AP83; 1:25 dilution) and VIA41. IIH6 and VIA41 antibodies are monoclonal antibodies to the glycoepitope of $\alpha$-DG $(20,21)$, and AP83 is a polyclonal antibody to the Ce-terminus of $\beta$-DG (19), all of which have been described previously.

\section{$\underline{\text { Glycoprotein enrichment and Western blot analysis }}$}

Half of the quadricep muscle was solubilized in $1 \mathrm{~mL}$ Tris-buffered saline (TBS) containing $1 \%$ Triton X-100 and protease inhibitors. The solubilized fraction was incubated with 200 
Yonekawa et al.

microliters of WGA-agarose bead slurry (Vector Laboratories, Burlingame, CA) overnight at $4^{\circ} \mathrm{C}$. Pellets formed from the beads and were washed three times in $1 \mathrm{~mL}$ TBS containing $0.1 \%$ Triton X-100 (15). The beads were then either directly mixed with SDS-polyacrylamide gel electrophoresis (PAGE) loading buffer (for western blotting, ligand overlay) or eluted with $1 \mathrm{~mL}$ TBS containing $0.1 \%$ Triton X-100 and $300 \mathrm{mM} \mathrm{N-acetyl-glucosamine} \mathrm{(for} \mathrm{solid-phase} \mathrm{binding}$ assay). Proteins were separated by $3-15 \%$ SDS-PAGE and transferred to polyvinylidene fluoride-FL (PVDF-FL, Millipore Sigma) membranes. The membranes were incubated with a sheep polyclonal antibody to human DG (AF6868; R\&D Systems, 1:100 dilution) and a mouse monoclonal antibody to a glycoepitope on the sugar chain of $\alpha$-DG (IIH6; 1:100 dilution) followed by IRDye® 800CW dye-conjugated goat anti-sheep IgG (LI-COR, 926-32214) and goat anti-mouse IgM (LI-COR, 926-32280), respectively.

\section{Ligand overlay assay}

Ligand overlay assays were performed on PVDF-FL membranes using mouse EngelbrethHolm-Swarm (EHS) laminin (ThermoFisher, 23017015). Briefly, PVDF-FL membranes were blocked in laminin binding buffer (LBB: $10 \mathrm{mM}$ triethanolamine, $140 \mathrm{mM} \mathrm{NaCl}, 1 \mathrm{mM} \mathrm{MgCl}$, $1 \mathrm{mM} \mathrm{CaCl}_{2}, \mathrm{pH} 7.6$ ) containing $5 \%$ milk followed by incubation with laminin overnight at $4^{\circ} \mathrm{C}$ in LBB containing 3\% bovine serum albumin (BSA). Membranes were washed and incubated with anti-laminin antibody (L9393; Sigma-Aldrich, 1:100 dilution) followed by IRDye® 800CW dye-conjugated donkey anti-rabbit IgG (LI-COR, 926-32213).

\section{Solid-phase assay}

A solid-phase laminin binding assay was performed as described previously (14). Briefly, WGA eluates were diluted 1:50 in TBS and coated on polystyrene ELISA microplates (Costar 3590) overnight at $4{ }^{\circ} \mathrm{C}$. Plates were washed in LBB and blocked for two hours in $3 \%$ BSA/LBB at RT. 
Mouse EHS laminin was diluted in 1\% BSA/LBB and applied for one hour at RT. The wells were washed with 1\% BSA/LBB and incubated for one hour with L9393 (1:5,000 dilution) in 3\% BSA/LBB followed by incubation with HRP-conjugated anti-rabbit IgG (Invitrogen, 1:5,000 dilution) in 3\% BSA/LBB for 30 minutes. Plates were developed with o-phenylenediamine dihydrochloride and $\mathrm{H}_{2} \mathrm{O}_{2}$, and reactions were stopped with $2 \mathrm{~N} \mathrm{H}_{2} \mathrm{SO}_{4}$. Absorbance per well was read at $490 \mathrm{~nm}$ by a microplate reader.

\section{mRNA expression analysis}

Quadricep muscle and heart cryosections were collected into tubes and stored at $-80^{\circ} \mathrm{C}$ until use. Total RNA was isolated using an RNeasy Mini kit (Qiagen, Venlo, Netherlands) and cDNA was generated using a QuantiTect Reverse Transcription Kit (Qiagen). For gene expression analysis, a QX100 droplet digital PCR (ddPCR) system (Bio-Rad, Pleasanton, CA) was used. The ddPCR reaction mixture consisted of 10 microliters of a $2 \times$ EvaGreen Supermix (Bio-Rad), 2 microliters of primers, and 5 microliters of cDNA sample in a final volume of 20 microliters. The entire reaction mixture was loaded into a disposable plastic cartridge (Bio-Rad) together with 70 microliters of droplet generation oil (Bio-Rad) and placed in the droplet generator (Bio-Rad). After processing, the droplets generated from each sample were transferred to a 96-well PCR plate (Eppendorf, Hamburg, Germany). PCR amplification was carried out on a T100 thermal cycler (Bio-Rad) using a thermal profile beginning at $95^{\circ} \mathrm{C}$ for five minutes, followed by 40 cycles of $95^{\circ} \mathrm{C}$ for 30 seconds and $60^{\circ} \mathrm{C}$ for 60 seconds, one cycle of $90^{\circ} \mathrm{C}$ for five minutes, and ending at $4^{\circ} \mathrm{C}$. After amplification, the plate was loaded on the droplet reader (Bio-Rad) and the droplets from each well of the plate were read automatically at a rate of 32 wells per hour. ddPCR data were analyzed with QuantaSoft analysis software (Bio-Rad), and the quantification of the target molecule was presented as the number of copies per microliter of PCR mixture. The 
Yonekawa et al.

oligonucleotides used for amplification are listed in Supplementary Table S2.

\section{$\underline{\text { Targeted metabolomics }}$}

Forty microliters of plasma was vortexed with 720 microliters of ice cold 1:1

methanol/acetonitrile to extract metabolites and incubated for one hour at $-20^{\circ} \mathrm{C}$. Metabolite

extracts were centrifuged for 10 minutes at $21,000 \mathrm{x}$ g to pellet precipitated protein. Supernatants

were transferred to sample vials and dried using a speed-vac. The resulting dried metabolite

extracts were derivatized using methoxyamine hydrochloride (MOX) and N,O-

Bis(trimethylsilyl)trifluoroacetamide (TMS) and examined by gas chromatography-mass

spectrometry (GC-MS), as previously described $(37,38)$. Briefly, dried extracts were

reconstituted in 30 microliters of $11.4 \mathrm{mg} / \mathrm{ml} \mathrm{MOX}$ in anhydrous pyridine, vortexed for five

minutes, and heated for one hour at $60^{\circ} \mathrm{C}$. Next, 20 microliters of TMS was added to each

sample, which were then vortexed for one minute and heated for 30 minutes at $60^{\circ} \mathrm{C}$. Samples

were immediately analyzed using GC-MS. GC separation was conducted on a Thermo Trace

1300 GC fitted with a TraceGold TG-5SilMS column. One microliter of derivatized sample was

injected into the GC operating under the following conditions: split ratio $=20-1$, split flow $=24$

microliters/minute, purge flow $=5 \mathrm{ml} /$ minute, carrier mode $=$ Constant Flow, and carrier flow

rate $=1.2 \mathrm{ml} /$ minute. The GC oven temperature gradient was as follows: $80^{\circ} \mathrm{C}$ for 3 minutes,

increasing at a rate of $20^{\circ} \mathrm{C} /$ minute to $280^{\circ} \mathrm{C}$, and holding at a temperature at $280^{\circ} \mathrm{C}$ for 8

minutes. Metabolites were detected using a Thermo ISQ 7000 mass spectrometer operated from 3.90 to 21.00 minutes in EI mode $(-70 \mathrm{eV})$ using select ion monitoring (SIM). EI fragmented metabolites were identified by the $\mathrm{m} / \mathrm{z}$ of fragments at unique chromatographic retention times corresponding to previously analyzed reference standards. Peak intensities were corrected using 
Yonekawa et al.

the NOREVA tool (39). Peak intensities from six unique experiments were normalized to total signal per sample and set relative to WT for final analysis.

\section{$\underline{\text { Statistical analysis }}$}

All data in the present study are shown as the means \pm SEM unless otherwise indicated. The number of sampled units, $\mathrm{n}$, upon which we reported statistics, is the single mouse for the in vivo experiments (one mouse is $\mathrm{n}=1$ ). GraphPad Prism 7 software was used for statistical analyses. The statistical analysis performed for each data set is indicated in the figure legends. $\mathrm{P}<0.05$ was considered significant. For survival, treated mice were compared with untreated mice by

Kaplan-Meier log-rank test. For all figures, ${ }^{*} p<0.05,{ }^{* *} p<0.01, * * * p<0.001$, and $* * * * p<$ 0.0001 were used. 
Yonekawa et al.

\section{REFERENCES}

1. J.M. Crudele. J.S. Chamberlain. AAV-based gene therapies for the muscular dystrophies. Hum. Mol. Genet. 28, R102-R107 (2019).

2. Y.L. Min, R. Bassel-Duby, E.N. Olson. CRISPR Correction of Duchenne Muscular Dystrophy. Annu. Rev. Med. 70, 239-255 (2019).

3. N. Elangkovan and G. Dickson. Gene Therapy for Duchenne Muscular Dystrophy. J. Neuromuscul. Dis. 10.3233/JND-210678 (2021).

4. V. Himič and K.E. Davies. Evaluating the potential of novel genetic approaches for the treatment of Duchenne muscular dystrophy. Eur. J. Hum. Genet. 29, 1369-1376 (2021).

5. J.R. Mendell, S.A. Al-Zaidy, L.R. Rodino-Klapac, K. Goodspeed, S.J. Gray, C.N. Kay, S.L. Boye, S.E. Boye, L.A. George, S. Salabarria, M. Corti, B.J. Byrne, J.P. Tremblay. Current Clinical Applications of In Vivo Gene Therapy with AAVs. Mol. Ther. 29, 464-488 (2021).

6. J.R. Mendell, S. Al-Zaidy, R. Shell, W.D. Arnold, L.R. Rodino-Klapac, T.W. Prior, L. Lowes, L. Alfano, K. Berry, K. Church, J.T. Kissel, S. Nagendran, J. L’Italien, D.M. Sproule, C. Wells, J.A. Cardenas, M.D. Heitzer, A. Kasper, S. Corcoran, L. Braun, S. Likhite, C. Miranda, K. Meyer, K. Foust, A.H. Burghes, B.K. Kaspar. Single-Dose GeneReplacement Therapy for Spinal Muscular Atrophy. N. Engl. J. Med. 377, 1713-1722 (2017).

7. P. Gregorevic, M.J. Blankinship, J.M. Allen, R.W. Crawford, L. Meuse, D.G. Miller, D.W. Russell, J.S. Chamberlain. Systemic delivery of genes to striated muscles using adenoassociated viral vectors. Nat. Med. 10, 828-834 (2004).

8. P. Gregorevic, J.M. Allen, E. Minami, M.J. Blankinship, M. Haraguchi, L. Meuse, E. Finn, M.E. Adams, S.C. Froehner, C.E. Murry, J.S. Chamberlain. rAAV6-microdystrophin 
Yonekawa et al.

preserves muscle function and extends lifespan in severely dystrophic mice. Nat. Med. 12, 787-789 (2006).

9. P. Gregorevic, M.J. Blankinship, J.M. Allen, J.S. Chamberlain. Systemic microdystrophin gene delivery improves skeletal muscle structure and function in old dystrophic mdx mice. Mol. Ther. 16, 657-664 (2008).

10. J. Watchko, T. O’Day, B. Wang, L. Zhou, Y. Tang, J. Li, X. Xiao. Adeno-associated virus vector-mediated minidystrophin gene therapy improves dystrophic muscle contractile function in mdx mice. Hum. Gen. Ther. 13, 1451-1460 (2002).

11. R.A. Potter, D.A. Griffin, K.N. Heller, E.L. Peterson, E.K. Clark, J.R. Mendell, L.R. Rodino-Klapac. Dose-Escalation Study of Systemically Delivered rAAVrh74.MHCK7.micro-dystrophin in the $m d x$ Mouse Model of Duchenne Muscular Dystrophy. Hum. Gene. Ther. 32, 375-389 (2021).

12. R. Barresi, D.E. Michele, M. Kanagawa, H.A. Harper, S.A. Dovico, J.S. Satz, S.A. Moore, W. Zhang, H. Schachter, J.P. Dumanski, R.D. Cohn, I. Nishino, K.P. Campbell. LARGE can functionally bypass alpha-dystroglycan glycosylation defects in distinct congenital muscular dystrophies. Nat. Med. 10, 696-703 (2004).

13. C.H. Vannoy, L. Xu, E. Keramaris, P. Lu, X. Xiao, Q.L. Lu. Adeno-associated virusmediated overexpression of LARGE rescues $\alpha$-dystroglycan function in dystrophic mice with mutations in the fukutin-related protein. Hum. Gene. Ther. Methods 25, 187-196 (2014).

14. M. Yu, Y. He, K. Wang, P. Zhang, S. Zhang, H. Hu. Adeno-associated viral-mediated $L A R G E$ gene therapy rescues the muscular dystrophic phenotype in mouse models of dystroglycanopathy. Hum Gene Ther. 24, 317-330 (2013). 
Yonekawa et al.

15. K.H. Holt, L.E. Lim, V. Straub, D. P. Venzke, F. Duclos, R.D. Anderson, B.L. Davidson, K.P. Campbell. Functional rescue of the sarcoglycan complex in the BIO 14.6 hamster using delta-sarcoglycan gene transfer. Mol. Cell 1, 841-848 (1998).

16. D.E. Michele, R. Barresi, M. Kanagawa, F. Saito, R.D. Cohn, J.S. Satz, J. Dollar, I. Nishino, R.I. Kelley, H. Somer, V. Straub, K.D. Mathews, S.A. Moore, K.P. Campbell. Posttranslational disruption of dystroglycan-ligand interactions in congenital muscular dystrophies. Nature 418, 417-421 (2002).

17. S.A. Moore, F. Saito, J. Chen, D.E. Michele, M.D. Henry, A. Messing, R.D. Cohn, S.E. Ross-Barta, S. Westra, R.A. Williamson, T. Hoshi, K.P. Campbell. Deletion of brain dystroglycan recapitulates aspects of congenital muscular dystrophy. Nature 418, 422-425 (2002).

18. C. Godfrey, A.R. Foley, E. Clement, F. Muntoni. Dystroglycanopathies: coming into focus. Curr. Opin. Genet. Dev. 21, 278-285 (2011).

19. O. Ibraghimov-Beskrovnaya, J.M. Ervasti, C.J. Leveille, C.A. Slaughter, S.W. Sernett, K.P. Campbell. Primary structure of dystrophin-associated glycoproteins linking dystrophin to the extracellular matrix. Nature 355, 696-702 (1992).

20. J.M. Ervasti, K. Ohlendieck, S.D. Kahl, M.G. Gaver, K.P. Campbell. Deficiency of a glycoprotein component of the dystrophin complex in dystrophic muscle. Nature 345, 315319 (1990).

21. J.M. Ervasti, K.P. Campbell. Membrane organization of the dystrophin-glycoprotein complex. Cell 66, 1121-1131 (1991).

22. J.M. Ervasti, K.P. Campbell. A role for the dystrophin-glycoprotein complex as a transmembrane linker between laminin and actin. J. Cell Biol. 122, 809-823 (1993). 
Yonekawa et al.

23. K.I. Inamori, T. Yoshida-Moriguchi, Y. Hara, M.E. Anderson, L. Yu, K.P. Campbell.

Dystroglycan function requires xylosyl- and glucuronyltransferase activities of LARGE.

Science 355, 93-96 (2012).

24. T. Yoshida-Moriguchi, K.P. Campbell. Matriglycan: a novel polysaccharide that links dystroglycan to the basement membrane. Glycobiology 25, 702-713 (2015).

25. C. Longman, M. Brockington, S. Torelli, C. Jimenez-Mallebrera, C. Kennedy, N. Khalil, L. Feng, R.K. Saran, T. Voit, L. Merlini, C.A. Sewry, S.C. Brown, F. Muntoni. Mutations in the human LARGE gene cause MDC1D, a novel form of congenital muscular dystrophy with severe mental retardation and abnormal glycosylation of alpha-dystroglycan. Hum. Mol. Genet. 12, 2853-2861 (2003).

26. N.F. Clark, S. Maugenre, A. Vandebrouck, J.A. Urtizberea, T. Willer, R.A. Peat, F. Gray, C. Bouchet, H. Manya, S. Vuillaumier-Barrot, T. Endo, E. Chouery, K.P. Campbell, A. Mégarbané, P. Guicheney. Congenital muscular dystrophy type 1D (MDC1D) due to a large intragenic insertion/deletion, involving intron 10 of the LARGE gene. Eur. J. Hum. Genet. 19, $452-457$ (2011).

27. K.G. Meilleur, K. Zukosky, L. Medne, P. Fequiere, N. Powell-Hamilton, T.L. Winder, A. Alsaman, A.W. El-Hattab, J. Dastgir, Y. Hu, S. Donkervoort, J.A. Golden, R. Eagle, R. Finkel, M. Scavina, I.C. Hood, L.B. Rorke-Adams, C.G. Bönnemann. Clinical, pathologic, and mutational spectrum of dystroglycanopathy caused by LARGE mutations. $J$. Neuropathol. Exp. Neurol. 73, 425-441 (2014).

28. P.W. Lane, T.C. Beamer, D.D. Myers. Myodystrophy, a new myopathy on chromosome 8 of the mouse. J. Hered. 67, 135-138 (1976). 
Yonekawa et al.

29. P.K. Grewal, P.J. Holzfeind, R.E. Bittner, J.E. Hewitt. Mutant glycosyltransferase and altered glycosylation of alpha-dystroglycan in the myodystrophy mouse. Nat. Genet. 28, $151-154$ (2001).

30. P.J. Holzfeind, P.K. Grewal, H.A. Reitsamer, J. Kechvar, H. Lassmann, H. Hoeger, J.E. Hewitt, R.E. Bittner. Skeletal, cardiac and tongue muscle pathology, defective retinal transmission, and neuronal migration defects in the Large(myd) mouse defines a natural model for glycosylation-deficient muscle-eye-brain disorders. Hum. Mol. Genet. 11, 26732687 (2002).

31. A. Lindsay, C.M. Chamberlain, B.A. Witthuhn, D.A. Lowe, J.M. Ervasti. Dystrophinopathyassociated dysfunction of Krebs cycle metabolism. Hum. Mol. Genet. 28, 942-951 (2018).

32. J. Strakova, F. Kamdar, D. Kulhanek, M. Razzoli, D.J. Garry, J.M. Ervasti, A. Bartolomucci, D. Townsend. Integrative effects of dystrophin loss on metabolic function of the mdx mouse. Sci Rep. 8, 13624 (2018).

33. P. Spitali, K. Hettne, R. Tsonaka, E. Sabir, J.B. Hemerik, J.J. Goeman, E. Picillo, M. Ergoli, L. Politano, A. Aartsma-Rus. Cross-sectional serum metabolomic study of multiple forms of muscular dystrophy. J. Cell Mol. Med. 22, 2442-2448 (2018).

34. C.H. Vannoy, V. Leroy, K. Broniowska, Q.L. Lu. Metabolomics Analysis of Skeletal Muscles from FKRP-Deficient Mice Indicates Improvement After Gene Replacement Therapy. Sci. Rep. 9, 10070 (2019).

35. E.P. Rader, R. Turk, T. Willer, D. Beltrán, K.I. Inamori, T.A. Peterson, J. Engle, S. Prouty, K. Matsumura, F. Saito, M.E. Anderson, K.P. Campbell. Role of dystroglycan in limiting contraction-induced injury to the sarcomeric cytoskeleton of mature skeletal muscle. Proc. Natl. Acad. Sci. USA 113, 10992-10997 (2016). 
Yonekawa et al.

36. R. Han, E.P. Rader, J.R. Levy, D. Bansal, K.P. Campbell. Dystrophin deficiency exacerbates skeletal muscle pathology in dysferlin-null mice. Skelet. Muscle 1, 35 (2011).

37. J. A, J. Trygg, J. Gullberg, A.I. Johansson, P. Jonsson, H. Antti, S.L. Marklund, T. Moritz. Extraction and GC/MS analysis of the human blood plasma metabolome. Anal. Chem. 77, 8086-8094 (2005).

38. J. Cox, S. Williams, K. Grove, R.H. Lane, K.M. Aagaard-Tillery. A maternal high-fat diet is accompanied by alterations in the fetal primate metabolome. Am. J. Obstet. Gynecol. 201, 281.e1-281.e9 (2009).

39. B. Li, J. Tang, Q. Yang, S. Li, X. Cui, Y. Li, Y. Chen, W. Xue, X. Li, F. Zhu. NOREVA: normalization and evaluation of MS-based metabolomics data. Nucleic Acids Res. 45, W162-W170 (2017). 


\section{Yonekawa et al.}

\section{END NOTES}

\section{Acknowledgements}

We thank Keith Garringer for technical assistance and the Viral Vector Core at the University of Iowa for generating the adeno-associated viral vector. ddPCR analyses presented herein were obtained at the Genomics Division of the Iowa Institute of Human Genetics, which is supported, in part, by the University of Iowa Carver College of Medicine. We are grateful to Drs. Jennifer Barr and Christine Blaumueller of the Scientific Editing and Research Communication Core at the University of Iowa Carver College of Medicine for critical reading of the manuscript. We are grateful to Amber Mower and Jaeda Harmon for assistance with administrative support.

\section{Authors' contributions}

T.Y. co-designed the project, carried out the experimental work, analyzed and interpreted the data, and co-wrote the manuscript. S.E.H., M.A.C., M.E.A., A.J.R., H.O., and A.D.P. conducted experimental work and analyzed and interpreted the data. D.V. generated essential reagents. E.B.T. analyzed and interpreted the data, co-wrote the manuscript, and supervised the research. Corresponding author K.P.C. co-designed the project, analyzed and interpreted the data, cowrote the manuscript, and supervised the research.

\section{Author Information}

The authors declare no competing financial interests. Correspondence and requests for materials should be addressed to K.P.C. (kevin-campbell@uiowa.edu). 
bioRxiv preprint doi: https://doi.org/10.1101/2021.10.28.466309; this version posted October 28, 2021. The copyright holder for this preprint (which was not certified by peer review) is the author/funder, who has granted bioRxiv a license to display the preprint in perpetuity. It is made available under aCC-BY 4.0 International license.

Yonekawa et al.

\section{Supplementary Materials}

Figures S1-S6

Data Tables S1 and S2 
Yonekawa et al.
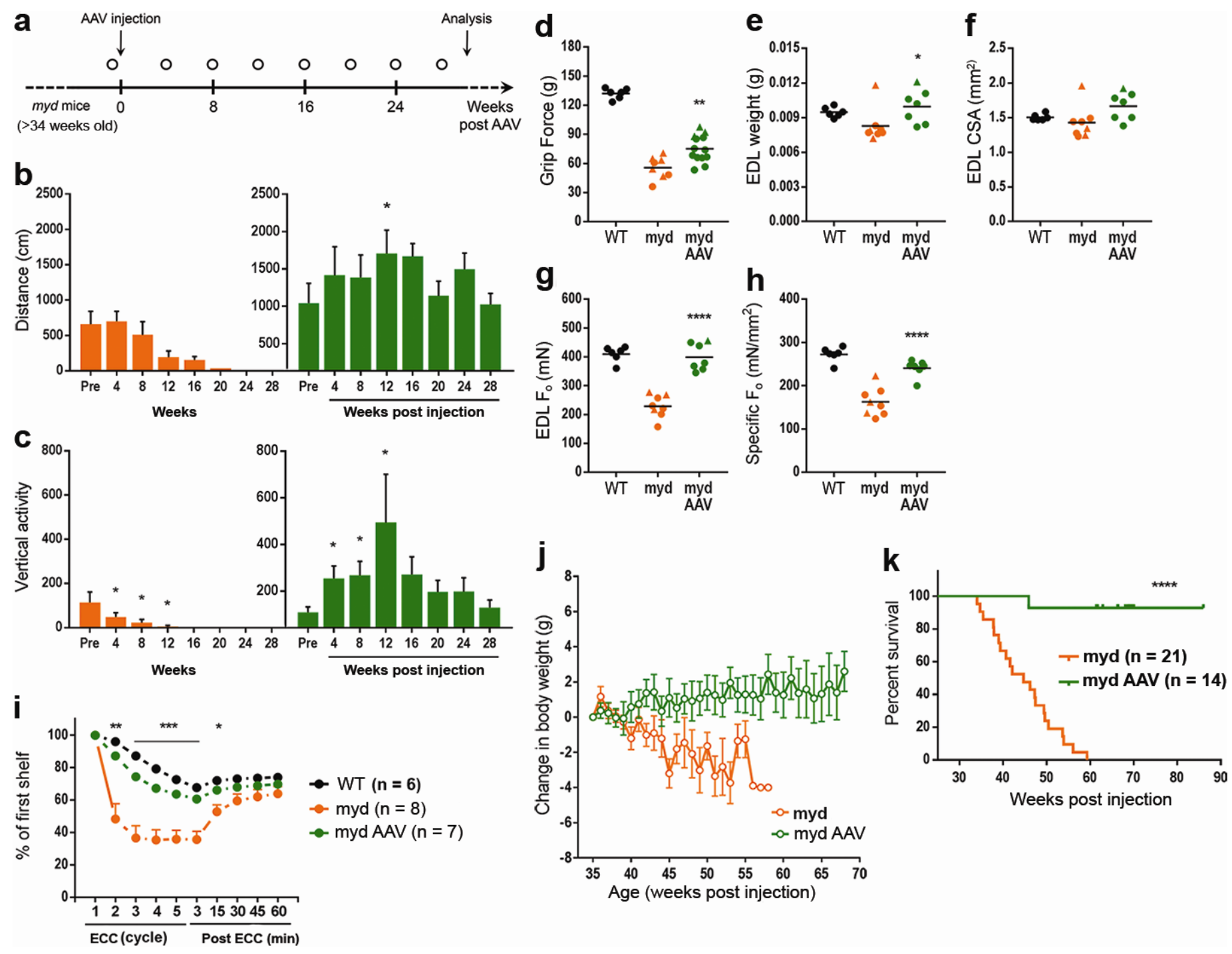

Figure 1 | Large1 gene transfer improves skeletal muscle function and extends survival.

a, Experimental outline. Mice were weighed weekly; open circle, locomotor activity determined. b, c Spontaneous locomotion (distance) and rearing (vertical activity). Untreated, orange; treated, green. d-h, Forelimb grip strength d, EDL muscle weight e, EDL muscle CSA f, EDL isometric tetanic force $\left(\mathrm{F}_{\mathrm{o}}\right), \mathbf{g}$, specific isometric tetanic force $\left(\mathrm{F}_{\mathrm{o}} / \mathrm{CSA}\right) \mathbf{h}$, (black; C57BL/6J) (WT)); treated myd (myd AAV), age > 60 weeks, untreated myd (myd), age $46.5 \pm 6.5$ weeks. i, Percentages of $F_{o}$ in mice at indicated time after eccentric contraction (ECC), relative to $F_{o}$ at $1^{\text {st }}$ ECC. $\mathbf{j}$, Changes in body weight relative to weight at 35 weeks of age. $\mathbf{k}$, Survival curves of mice in the indicated treated groups. Symbols, individual mice; bars, means \pm SEM. C57, black; myd, orange; myd AAV, green. 
Yonekawa et al.
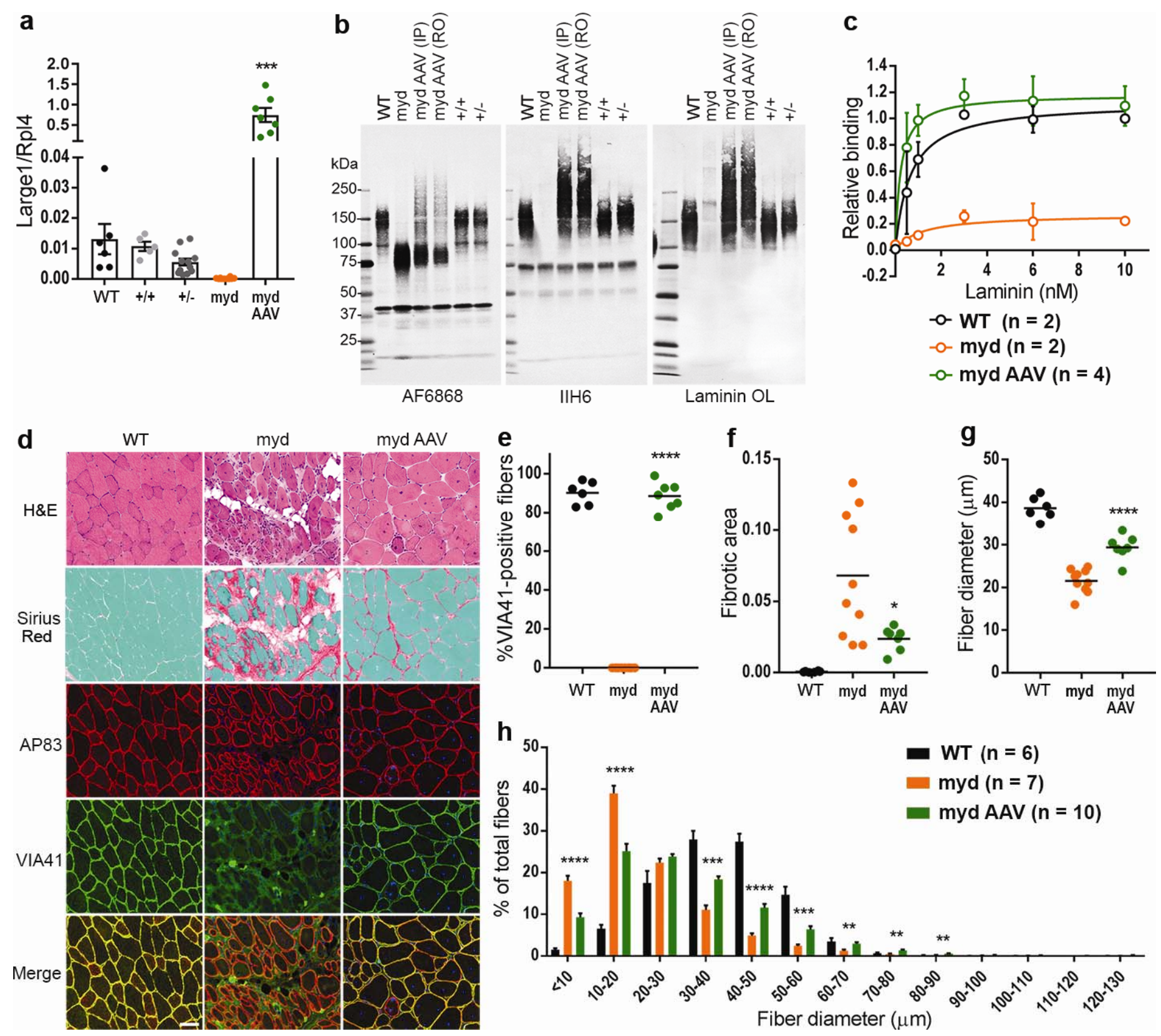

Figure 2 | AAVLarge1 restores matriglycan on $\alpha$-DG and laminin binding in skeletal muscles, which alleviates muscle pathology in myd mice.

a, Large1 expression. b, Western blot of core $\alpha$-DG and $\beta$-DG (AF6868), matriglycan-positive $\alpha$-DG (IIH6), or laminin (laminin OL) in a. c, Solid-phase binding assay. d, Representative cryosections stained with H\&E or Sirius Red \& Fast Green, or used for immunofluorescence: $\beta$ DG (AP83); matriglycan-positive $\alpha$-DG (VIA41). Scale bar: $50 \mu \mathrm{m}$. e-h, Quantitative analysis of sections in d. e, VIA41-positive fibers. f, Connective tissue deposition. g, Average Feret's diameter of fibers. h, Percentage of fibers of indicated diameter. Symbols, individual mice; bars, means \pm SEM. WT, C57B1/6J; +/+, Large $^{+/+} ;+/-$, Large $^{+/-} ;$LC, littermate control; myd, untreated myd; myd AAV, AAVLargel injected myd mice; IP, intraperitoneal; RO, retroorbital. 
Yonekawa et al.
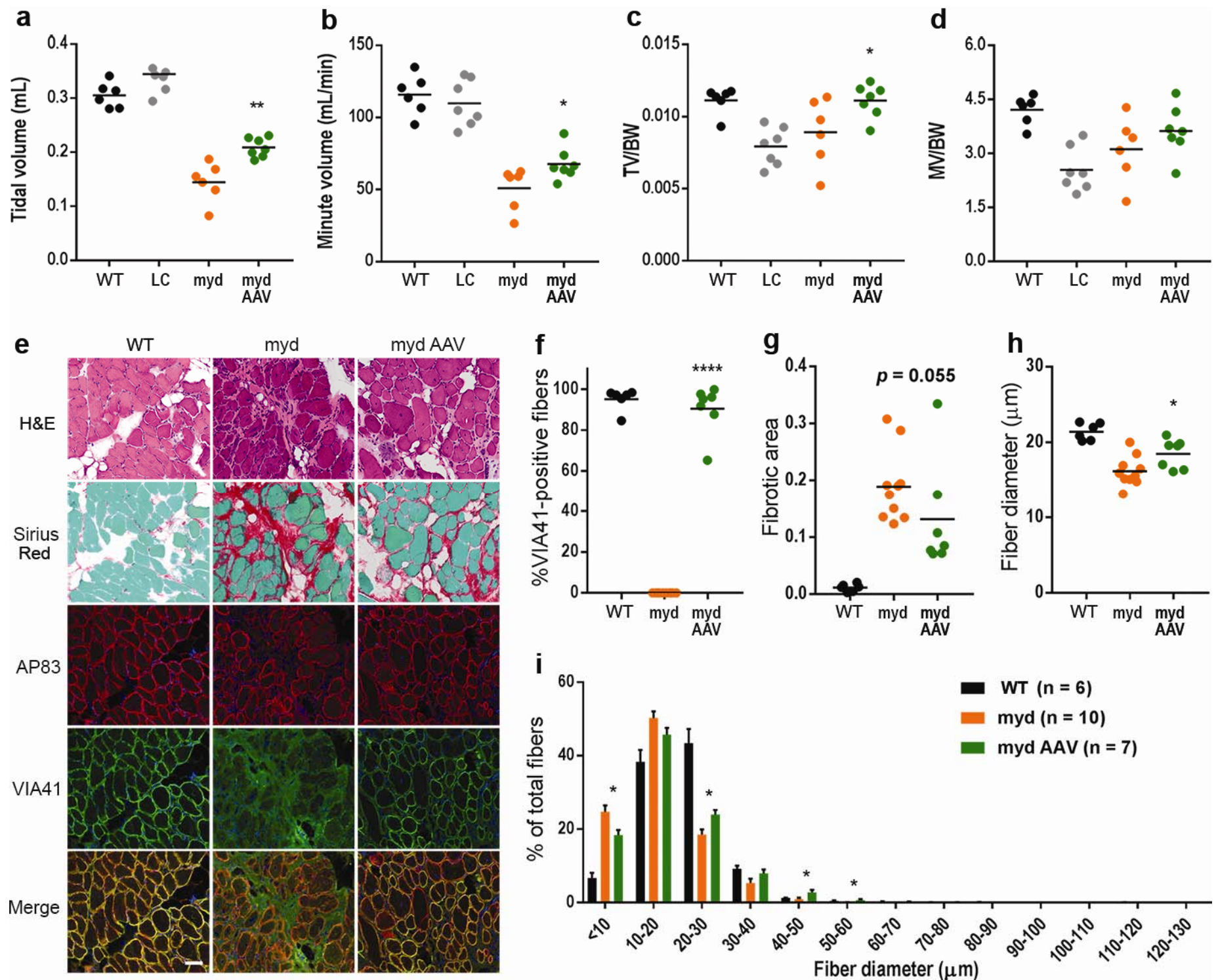

Figure 3 | Large1 gene transfer improves respiratory function and diaphragm pathology.

Whole body plethysmography for: a, Tidal volume, TV; b, Minute volume, MV; c, Tidal volume normalized to bodyweight, TV/BW; d, Minute volume normalized to weight, MV/BW. e, Representative cryosections. Sections stained with H\&E or Sirius Red \& Fast Green, or used for immunofluorescence: $\beta$-DG (AP83) and matriglycan-positive $\alpha$-DG (VIA41). Scale bar: $50 \mu \mathrm{m}$. $\mathbf{f - i ,}$ Quantitative analysis of sections in e. f, VIA41-positive fibers. g, Connective tissue deposition. h, Average Feret's diameter of fibers. i, Percentage of fibers of indicated diameter. Symbols, individual mice; bars, means \pm SEM. WT, C57BL/6J; myd, untreated myd; myd AAV, AAVLargel injected myd mice; LC, littermate control $\left(\right.$ Large $^{+/+}$or Large $\left.e^{+/-}\right)$. 
Yonekawa et al.
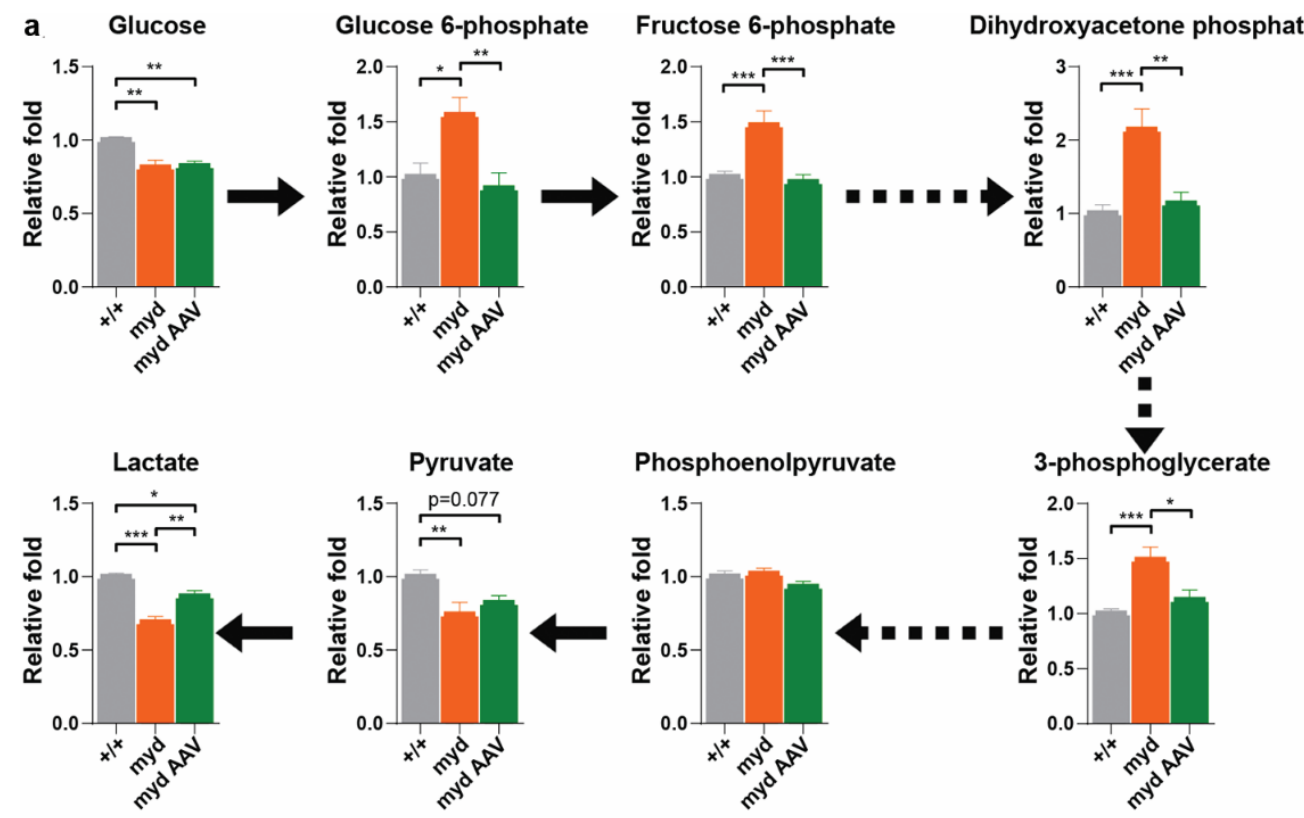

b
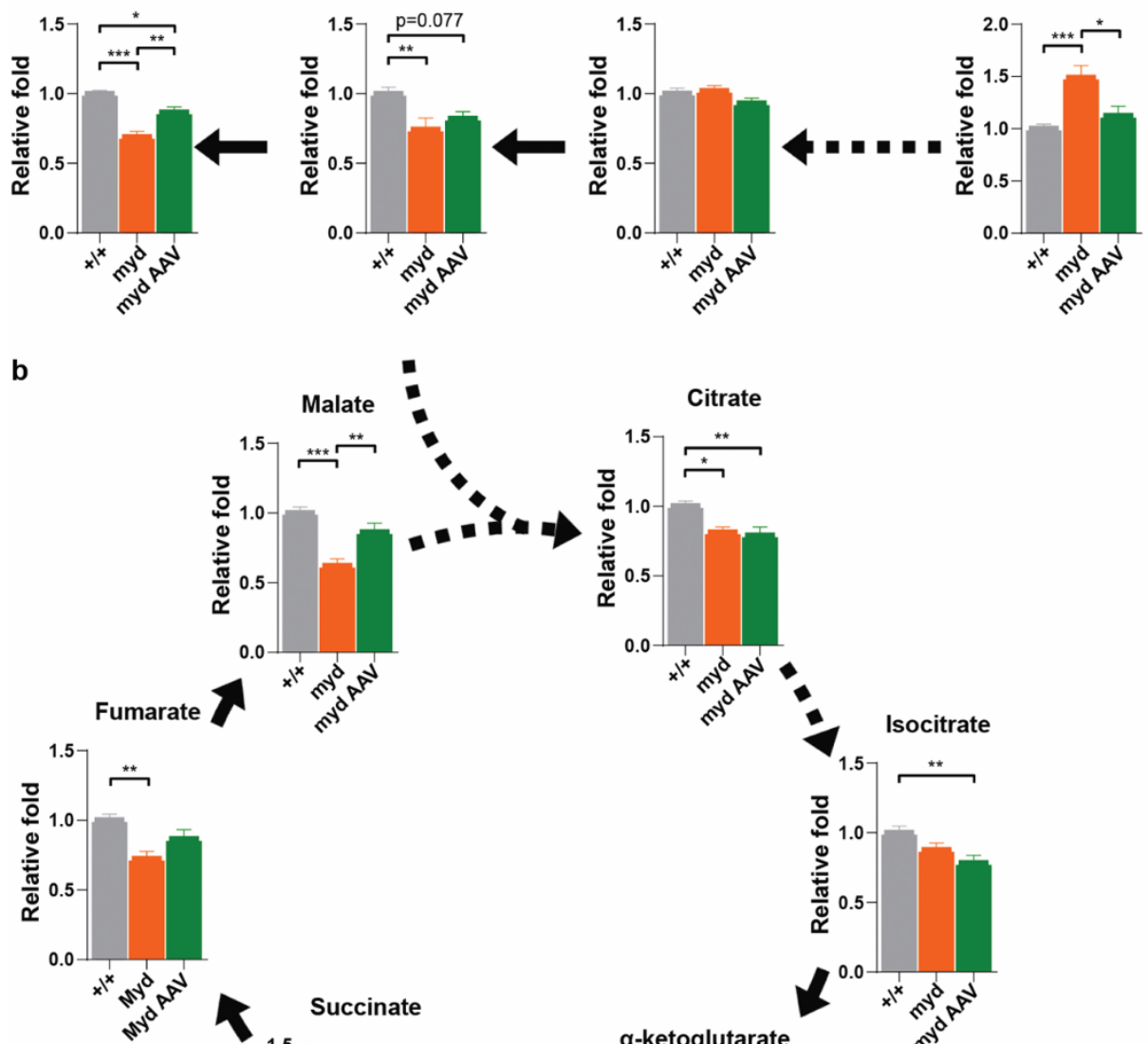

Isocitrate
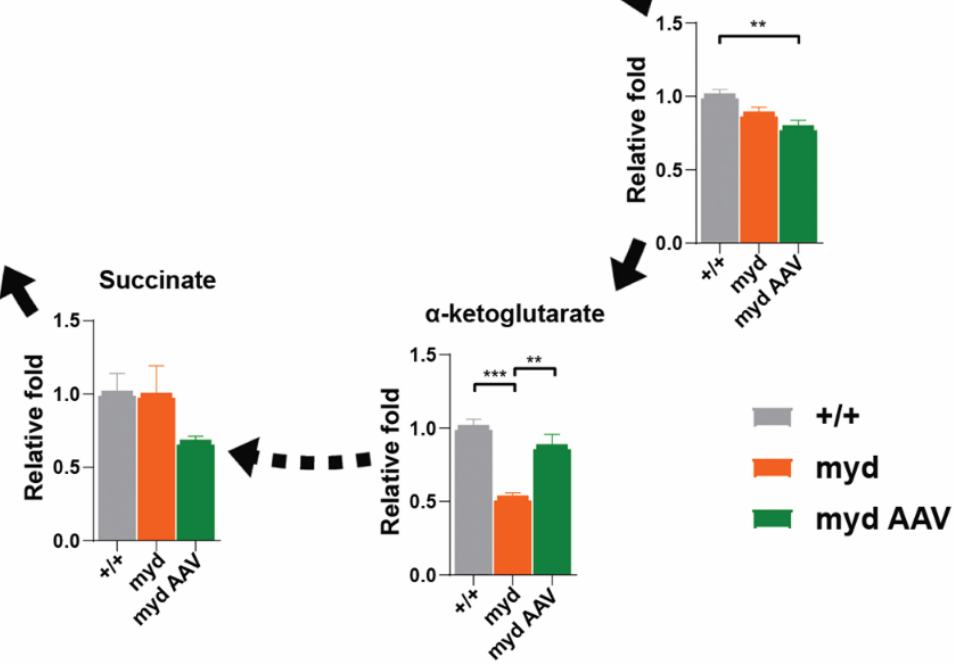

Figure 4 | Large1 is required for normal glycolytic and TCA cycle plasma profiles.

Relative fold change of plasma: a, glycolytic and $\mathbf{b}$, intermediate TCA cycle metabolites from Large $^{+/+}(+/+$, grey bars, $\mathrm{n}=11)$, untreated myd (myd, orange bars, $\left.\mathrm{n}=7\right)$, and myd mice treated with AAVLargel (myd AAV, green bars, $\mathrm{n}=6$ ), solid and dashed arrows represent single and multiple metabolic reactions, respectively, ${ }^{*} \mathrm{p}<0.05$, ${ }^{* *} \mathrm{p}<0.01,{ }^{*} * \mathrm{p}<0.001$. Analysis by ordinary one-way ANOVA followed by post hoc Tukey's multiple comparison test. Data presented as mean \pm SEM. 